\title{
Attitudinal barriers to delivery of race-targeted pharmacogenomics among informed lay persons
}

Celeste Condit, $P h D^{1}$, Alan Templeton, $P h D^{2}$, Benjamin R. Bates, $P h D^{1}$, Jennifer L. Bevan, $P h D^{3}$, and Tina M. Harris, $P h D^{1}$

\begin{abstract}
Objectives: To ascertain attitudes of prospective patients relevant to the delivery of race-based pharmacogenomics. Methods: Written anonymous survey and qualitative responses in two sets of reactance format focus groups over-sampled for minority groups in urban, suburban, and rural communities conducted from February through April, 2002 [ $N=104]$ and August through November, 2002 [ $N=120]$. Results: Participants do not associate "races" exclusively with continental clusters. They have incomplete knowledge of their recent ancestors (39.6\% do not know all their biological grandparents). They would be highly suspicious of race-labeled drugs; with $47.5 \%$ saying they would be very suspicious of their safety and $40.6 \%$ indicating they would be very suspicious of their efficacy. A substantial minority of African-American participants (13.2\%) would prefer to take the drugs designated for European Americans. Effect of discussion of race-based medicine on racial attitudes is ambiguous. Conclusions: Patient knowledge of ancestry and suspicion of race-designated drugs constitute substantial barriers that need to be incorporated in judging the likely effectiveness of race-based
\end{abstract} pharmacogenomics. Genet Med 2003:5(5):385-392.

Key Words: pharmacogenomics, race, genetic discrimination

Different people respond to different medicines in different ways. Depending on the medical treatment and condition at issue, these differences in response are influenced to varying degrees by particular genotypes. Because human genetic configurations vary based on geographic history, patterns of response to medicines also vary based on the geographic history of an individual's ancestors. There is currently an intense debate about the extent to which socially identified race can be taken as a proxy for this geographic history of individual ancestry. ${ }^{1-7}$ Although there is general agreement that $99.9 \%$ of the human genome is shared among all persons, and that differences among continental groups represent only about $10 \%$ of that $0.1 \%$ of diversity in DNA base pairs, the potential clinical implications of the continental-based diversity remain unclear. ${ }^{3,8,9}$ To the extent that race provides a sufficiently precise proxy for human genetic variation, it might be possible and even useful to prescribe medicines based on race, and to perform diagnoses considering race as an informative biological variable. As Lee, Mountain, and Koenig report, ${ }^{3}$ there are already efforts to use race as such a pharmacogenomic indicator in products such as glaucoma treatments.

\footnotetext{
From the ${ }^{1}$ University of Georgia, Athens, Georgia; ${ }^{2}$ Washington University, St Louis, Missouri; and the ${ }^{3}$ University of Nevada, Las Vegas, Nevada.

Celeste M Condit, PhD, Department of Speech Communication, Terrell Hall, University of Georgia, Athens GA 30602.

Received: February 24, 2003.

Accepted: May 9, 2003.
}

DOI: 10.1097/01.GIM.0000087990.30961.72
There is not, however, an exact match between patterns of human genetic variation and socially designated race. Current data indicate that human genetic variation is not structured in a simple and orderly fashion, but rather is partially clinal, strongly but not fully clustered by continent, and at the local level is "mottled," sometimes having isolated distinct patches and sometimes featuring varying degrees of homogeneity. ${ }^{3,10,11}$ Likewise, the structure of our labels for race as a social category are also ordered in ways that operate at diverse levels of abstraction and incorporate geography and culture to varying degrees. These groupings also change over time and vary by political entity, with U.S., Canadian, and British governments all providing different legally mandated categories for racial classification.,12 Elite "racial" classifications seem to reflect the politics of immigration and changing demographics rather than timeless scientific or biological categories. In the U.S. in the 20th century, for example, the three numerically largest racialized groups are "European Americans," "African Americans," and "Hispanics/Latinos." Two of these are identified by region of origin, whereas the third has substantial ancestral inputs from three continents and is identified by language. More precise research-based understandings of how lay individuals understand the groupings signified by "races" need to be developed.

A precise delineation of the relationships between social groupings and geographic distribution of genes awaits additional research and detailed comparison. In the meantime it is clear that, although there is some overlap between some socially defined racial groupings and population genetic diversity ${ }^{4}$ the incompleteness of this overlap means that the utility of race-based pharmacogenomics will depend in some substantial measure on the workability of its delivery to patients. This 
will require both the ability to label patients by continent of ancestry accurately and patient acceptance of race-targeted medicine.

The ability to use race as a proxy for genetic inheritance implies that individuals can be properly assigned to a discrete race through appearance or social identity labels. Wilson et al. ${ }^{6}$ have dealt with some of the genetic insufficiencies of this assumption on a population basis. However, with regard to delivering a drug to an individual patient, the ability to select an appropriate race-targeted drug depends on the ability to identify the genetic homogeneity or heterogeneity of the patient's background. As multiple studies have indicated, intermixture of ancestry from multiple continents in U.S. populations among African Americans is in the range of $12 \%$ to $23 \%$ percent. In Hispanics/Latinos, this intermixture is the norm rather than the exception, with an average of 3\% African, 58\% Northern European, and 39\% North or South American backgrounds in Southwestern Hispanic/Latinos and a greater percentage of African backgrounds in Eastern Hispanics/Latinos. ${ }^{4}$ This suggests that a medically significant percentage of patients may bring alleles from different geographic backgrounds based on their particular heritage. Therefore, the ability to identify the multiple continental based inputs for a given patient depends to some substantial degree on the ability to identify their ancestry. There appears to be no data currently available about lay knowledge of the continent of ancestry of their parents, grandparents, or earlier ancestors.

There also appears to be no direct data about the issue of patient attitudes toward race-labeled drugs. In this article, we therefore report data about the understandings and attitudes of prospective patients that will impact the potential viability of race-based pharmacogenomics, specifically, (1) lay classification of "racial groups," (2) knowledge of personal heredity, (3) level of suspicion about the safety and efficacy of racedesignated drugs, (4) preferences of drugs when race-designated, and (5) impact of discussion of race-based medicine on attitudes about genetic difference.

\section{METHODS}

\section{Study protocol}

Lay individuals are not likely to be familiar with the term "pharmacogenomics," the underlying genetic issues, or the relationship of these issues to race. Consequently, opinion polls cannot be informative about likely lay response to race-labeled pharmacogenomic products and procedures. Therefore, we ran two separate series of focus groups in the Summer/Fall of 2001 (Study 1) and in the Spring of 2002 (Study 2) to explore lay attitudes about and understandings of the relationships among race, genetics, and medicine. The focus group setting allows participants to receive basic information about the phenomenon under issue and provide their responses in light of that information. This is sometimes called a "reactance format focus group," as opposed to focus groups where no information or other material is provided.

\section{Study 1}

In the Summer and Fall of 2001, we conducted 15 focus groups with 120 total participants. In order to enable honest discussion of sensitive issues about race, we segregated groups by racialized groupings of the participants. Seven groups had persons self-identifying as "Black" or "African American," seven groups had persons self-identifying as "White" or "European American," and one group had persons self-identifying as Latino or Hispanic. Moderators were matched by self-identified race. Sessions lasted slightly over two hours.

Participants were recruited by nomination and by snowball method from a community advisory board in three areas (Atlanta, a large urban area; Gainesville, a regional hub, formerly primarily agricultural, but in transition; and Athens, a University town). Community advisory boards were first asked to discuss what constituted their community. Then they were asked to nominate individuals who would represent the breadth of perspectives in their community. Those individuals were then called by research team members and invited to participate. They were told who they had been nominated by and offered $\$ 50$ to compensate them for transportation, child care costs, and time. Where needed, volunteers were asked to nominate additional participants (especially in order to increase representation from under-participating groups such as men). Approximately $50 \%$ of the nominees were reached by phone, and of those reached, approximately $46 \%$ (200) agreed to participate. Contact with all nominees was not attempted where sufficient numbers were recruited before their name was reached on the list. Of those who agreed to participate, approximately $60 \%$ actually showed up for the focus group meetings.

Participants were screened on initial telephone contact to ensure that they had only "lay" knowledge of genetics. They were asked how much they knew about genetics, and if they indicated that they had "professional knowledge" or "knew a lot" they were excluded. Moderators used a common series of questions, which had been developed by the research team and reviewed and revised by the three community advisory groups. Questions focused on general understandings of race and genetics and their implications for health. Moderators were encouraged to include follow-up probes or to revise wordings in questions to seek full exploration of the issues by as many participants as possible.

\section{Study 2}

As a follow-up, designed to focus more specifically on racebased medicine, a series of 10 reactance format focus groups $(N=104)$ were conducted in the Spring of 2002 (see Table 1). Moderators presented the following basic information by script in all groups: (1) "Genes come in versions that have different effects," (2) "therefore, some medicines are better for people who have version 1 rather than version 2 of that gene," (3) "groups who are socially defined as 'races' may have different geographic histories from each other," and (4) "therefore, medicine A may be more effective with the majority of one 'racial' group and medicine $\mathrm{B}$ may be more effective with the 
Table 1

Participant characteristics

\begin{tabular}{|c|c|c|c|c|c|c|}
\hline & Race & & Gender & & Income & Education \\
\hline \multirow[t]{7}{*}{ Study $1(N=120)$} & Black & 60 & Female & 67 & $15<\$ 25,000$ & $3.5 \%<$ high school \\
\hline & White & 52 & Male & 53 & $41=\$ 25-50,000$ & $15.7 \%$ HS graduate \\
\hline & Hispanic/Latino & 7 & & & $22=\$ 50-75,000$ & $23.5 \%$ some college \\
\hline & Native American & 1 & & & $25>\$ 75,000$ & 37.4\% B.S./B.A. \\
\hline & & & & & & $4.3 \%$ some grad school \\
\hline & & & & & & 13\% M.A./M.S. \\
\hline & & & & & & < 1\% J.D. \\
\hline \multirow[t]{6}{*}{ Study $2(N=104)$} & Black/AA & 61 & Female & 67 & $14<\$ 25,000$ & $2 \%<$ high school \\
\hline & White/EA & 24 & Male & 37 & $36=\$ 25-50,000$ & $24 \%$ HS graduate \\
\hline & Hispanic/Latino & 7 & & & $31=\$ 50-75,000$ & $38 \%$ some college \\
\hline & Multiracial & 12 & & & $9>\$ 75,000$ & $22 \%$ B.S./B.A. \\
\hline & & & & & & $11 \%$ some grad school \\
\hline & & & & & & 1\% J.D. \\
\hline
\end{tabular}

Numbers may not add to total $N$ and percentages may not add to 100 due to some participants not responding to specific questions.

majority of another group" (full script available on request). Moderators then raised four policy options for dealing with the variable effects of medicines on different social groups, including individual genotyping, race-based prescription, assignment of the same drug to everyone, and encouraging participants to generate their own options. Moderators encouraged all groups to explore advantages and disadvantages of all options, and moderators had a standard set of issues based on previous research to raise if groups did not raise them. In almost all cases, the groups articulated these standard issues without prompting. Before and after the discussion, participants were asked to take a written, anonymous survey to ascertain their private opinions in the absence of overt, immediate group pressure.

Five groups were composed of self-identified African Americans/Blacks, one included self-identified European Americans/Whites, two had approximately equal numbers of selfidentified European- and African Americans, one had selfidentified multiracial persons, and one had self-identified Hispanics/Latinos. African Americans were intentionally overrepresented because they are at risk of heavier negative impact from race-labeled medicine. ${ }^{13}$ Moderators were matched by self-identified race, with one integrated group being moderated by an African American female and one moderated by a European American female. Sessions lasted slightly over two hours.

Participants were recruited, screened, and remunerated as above. Of those reached, approximately 150 agreed to participate (contact with all nominees was not attempted because sufficient numbers were recruited before all names were reached on the list). Each participant provided informed written consent, and appropriate institutional review board approval was received. Approximately $42 \%$ of those reached by phone agreed to participate, and of those who agreed to participate, approximately $69 \%$ attended the focus group meetings. Some brought friends or family, who were also permitted to participate.

\section{RESULTS}

\section{Participants}

Participants are described in Table 1.

The target age for recruiting was 18 to 45 . Ages in Study 1 ranged from 18 to 51, with an average age of 32.6. Ages in Study 2 ranged from 18 to 64 , with an average age of 32.8 .

\section{Lay racial groupings}

In Study 1, participants were asked to "List Some Races." As Table 2 indicates, participants enumerated a combination of continentally based groupings ("African"), linguistically based groupings ("Hispanic"), national groupings ("Korean"), and regional groupings ("Latin American"). Only about half of the enumerated categories were continental. Although both the U.S. Census categories and the National Institutes of Health reporting requirements treat Latino/Hispanic as an "ethnic" group rather than a "race," participants appeared to treat it as a racial category. We coded "Black" and "White" as continental, because this is often interpreted by those proposing the oneto-one alignment between social grouping and underlying genetic structure as continental. ${ }^{4}$ However, it is not strictly continental, and could be listed under "other." In that case, the continental grouping would be substantially less than a majority of the cases. 
Table 2

Listing of races by focus group participants

\begin{tabular}{|c|c|c|c|c|c|c|c|c|c|}
\hline \multicolumn{2}{|c|}{ Continental groupings } & \multicolumn{2}{|c|}{ Regional groupings } & \multicolumn{2}{|c|}{ National groupings } & \multicolumn{2}{|c|}{$\begin{array}{l}\text { Linguistic } \\
\text { groupings }\end{array}$} & \multicolumn{2}{|l|}{ Other } \\
\hline Label & No. & Label & No. & Label & No. & Label & No. & Label & No. \\
\hline Black & 6 & West African & 1 & & & & & & \\
\hline African American & 2 & & & & & & & & \\
\hline White & 5 & & & & & & & & \\
\hline \multirow[t]{3}{*}{ Caucasian } & 4 & & & & & & & & \\
\hline & & Latin American & 1 & Mexican & 2 & Hispanic & 10 & & \\
\hline & & & & Cuban & 1 & Latino & 2 & & \\
\hline Asian & 5 & South Asian & 1 & Chinese & 1 & & & & \\
\hline \multirow[t]{2}{*}{ Asian American } & 2 & & & Korean & 2 & & & & \\
\hline & & & & Japanese & 1 & & & & \\
\hline Australian & 1 & & & Australian $^{a}$ & 1 & & & Aborigine & 2 \\
\hline \multirow[t]{2}{*}{ Native American } & 3 & & & & & & & & \\
\hline & & & & & & & & "Other" (census category) & 2 \\
\hline \multirow[t]{2}{*}{ Total } & 27 & & 3 & & 8 & & 12 & & 4 \\
\hline & $51 \%$ & & $4 \%$ & & $15 \%$ & & $23 \%$ & & $8 \%$ \\
\hline
\end{tabular}

Percentages do not add to $100 \%$ due to rounding.

${ }^{a}$ Australian was used once. Because it could be understood either as a continental or national grouping, we have placed it in both categories.

\section{Identification of ancestry}

To determine how well patients will be able to identify their full ancestry, in Study 2 we asked our respondents to identify how far back they knew their respective ancestors. The question read, "Please circle all of the following that you know about your biological family's heritage in enough detail to be able to confidently identify the geographic origin of your ancestors." Answers included the following: A) Don't know either parent, B) Know only one parent, C) Know both parents, D) Know some but not all of my grandparents, E) Know all of my grandparents, F) Know some but not all of my great grandparents, G) Know all of my great grandparents, and so forth through five generations. Of the participants, $8.9 \%$ did not know both of their biological parents (they knew either one or neither), and 39.6\% did not know all four of their grandparents (see Table 3). The difference in knowledge of grandparents between European Americans and all others (using a composite "minority" grouping) is statistically significant, with European Americans having greater knowledge of their ancestry (Fisher's exact test, $P=0.002$; the Pearson chi-square value comparing all groups independently is $12.79, P=0.012$ ). These results indicate that the ability to identify one's geographic ancestry in a way that rules out recent admixture and provides a homogeneous background for drug prescription or diagnosis is not reliable with a proportion of the population that is large enough to be of relevance in designing medical policy. Indeed, as the discussion below will indicate, the uncertainty in this variable is probably so great, that when combined with the probabilistic uncertainties in the utilities of the medicines themselves, it vitiates any hoped for increase in precision gained by using race for drug prescription.

Table 3

Knowledge of ancestors

\begin{tabular}{lc}
\hline How far back do you know your ancestry? & $\begin{array}{c}\text { Total } \\
\text { marked }\end{array}$ \\
\hline Don't know either parent & 3 \\
Know 1 parent & 6 \\
Know both parents & 80 \\
Know some grandparents & 38 \\
Know all grandparents & 50 \\
Know some great-grandparents & 47 \\
Know all great-grandparents & 21 \\
Know some great-great-grandparents & 26 \\
Know all great-great-grandparents & 3 \\
Know some great-great-great-grandparents & 20 \\
Know all great-great-great-grandparents & 3 \\
Know some great-great-great-great-grandparents & 13 \\
Know all great-great-great-great-grandparents & 3 \\
Know back more than 5 generations & 3 \\
\hline No
\end{tabular}

$N=99$. Two participants declined to respond. Participants were able to mark more than one category, as categories are not mutually exclusive. 
Table 4

How suspicious would you be that a drug designated as preferred for African Americans was not as SAFE as a drug designated as preferred for European Americans?

\begin{tabular}{|c|c|c|c|c|c|}
\hline & African American & European American & Hispanic/Latino & $\mathrm{Bi} /$ multiracial & Total \\
\hline Very suspicious & $52.6 \%(30)$ & $24 \%(6)$ & $86 \%(6)$ & $60 \%(6)$ & $48.5 \%(48)$ \\
\hline Moderately suspicious & $10.5 \%(6)$ & $16 \%(4)$ & $14 \%(1)$ & $30 \%(3)$ & $14.1 \%(14)$ \\
\hline Somewhat suspicious & $15.7 \%(9)$ & $20 \%(5)$ & & $1 \%(1)$ & $15.2 \%(15)$ \\
\hline Slightly suspicious & $8.8 \%(5)$ & $20 \%(5)$ & & & $10.1 \%(10)$ \\
\hline Not at all suspicious & $12.3 \%(7)$ & $20 \%(5)$ & & & $12.19 \%(12)$ \\
\hline Total & 57 & 25 & 7 & 10 & 99 \\
\hline
\end{tabular}

Percentages do not equal $100 \%$ due to rounding.

\section{Suspicions of race-based drugs}

Participants were also asked in the postdiscussion anonymous survey about their suspicions of race-based drugs. Specifically, the question read, "How suspicious would you be that a drug designated as preferred for African Americans was not as safe as a drug designated as preferred for European Americans?" (Answers ranged on a five point scale from $1=$ "Very suspicious" to $5=$ "Not at all suspicious.") As Table 4 indicates, the levels of suspicion reported were extremely high: $47.5 \%$ indicated that they would be "very suspicious" and only $11.9 \%$ indicated that they would be "not at all suspicious." Although levels of suspicion are very high in all groups, levels of suspicion in European Americans are lower and exhibit a statistically significant difference from "minorities" (a composite formed by combining results from members of all three of the other racialized groupings; minorities: mean $=1.99, \mathrm{SD}$ $=1.36$; European Americans mean $=2.96, \mathrm{SD}=1.49 ; t=$ $-3.02, P=0.003)$. We also asked "How suspicious would you be that a drug designated as preferred for African Americans was not as effective as a drug designated as preferred for European Americans?" As Table 5 indicates, the levels of suspicion here were only slightly lower: $40.6 \%$ indicated that they would be "very suspicious" and only $12.9 \%$ indicated that they would be "not at all suspicious." Again, levels of suspicion about effectiveness are also lower among European Americans than other groups (minorities mean $=2.11, \mathrm{SD}=1.35$; European Americans mean $=2.96, \mathrm{SD}=1.49 ; t=-2.656, P=0.009)$.

\section{Which drug would you want?}

A high level of suspicion may or may not translate into unwillingness to take a race-targeted drug. We therefore asked our participants if they would want to take a drug designated for African Americans or one designated for European Americans. In the case of our Latino/Hispanic participants, a drug designated for Hispanics/Latinos was an additional choice. All persons who self identified as European Americans indicated that they would prefer the drug designated for European Americans. Forty-six African Americans indicated that they would take the drug designated for African Americans, but 7 (13\%) indicated that they would take the European American drug. Four of the persons designating themselves as Hispanic/Latino indicated that they would prefer the drug designated for Hispanic/Latinos, while two indicated that they would prefer some "other" drug. Persons self-identified as having multiracial ancestry were roughly equally likely to choose the drug designated for African Americans, for European Americans, or "other."

We tested the null hypothesis that ethnic category is independent of choosing the drug for that ethnic category versus another drug. Because it is not clear what the expectation for the multiracial category should be, this group was excluded. Comparing European Americans to a composite grouping of Hispanics plus African Americans using Fisher's exact test yields a level of $P=0.0273$, indicating a significant difference in the likelihood that individuals from different racialized

Table 5

How suspicious would you be that a drug designated as preferred for African Americans was not as EFFECTIVE as a drug designated as preferred for European Americans?

\begin{tabular}{|c|c|c|c|c|c|}
\hline & African American & European American & Hispanic/Latino & Bi/multiracial & Total \\
\hline Very suspicious & $42.1 \%(24)$ & $24 \%(6)$ & $71.1 \%(5)$ & $60 \%(6)$ & $41.4 \%(41)$ \\
\hline Moderately suspicious & $21.1 \%(12)$ & $16 \%(4)$ & $28.6 \%(2)$ & $20 \%(2)$ & $20.2 \%(20)$ \\
\hline Somewhat suspicious & $15.8 \%(9)$ & $20 \%(5)$ & & $20 \%(2)$ & $16.2 \%(16)$ \\
\hline Slightly suspicious & $7.0 \%(4)$ & $20 \%(5)$ & & & $8.9 \%(9)$ \\
\hline Not at all suspicious & $14.0 \%(8)$ & $20 \%(5)$ & & & $13.3 \%(13)$ \\
\hline Total & 57 & 25 & 7 & 10 & 99 \\
\hline
\end{tabular}

Percentages do not equal $100 \%$ due to rounding. 
Table 6

If you were choosing for yourself, which drug would you want to try first?

Hispanicl African European

Latino American American Multi/biracial All

\begin{tabular}{|c|c|c|c|c|c|}
\hline For Hispanics/Latinos & 4 & & & & 4 \\
\hline For European Americans & & 7 & 24 & 3 & 34 \\
\hline For African Americans & & 46 & & 4 & 50 \\
\hline Other & 3 & & & 3 & 6 \\
\hline Total & 7 & 53 & 24 & 10 & 94 \\
\hline
\end{tabular}

groups would choose to select the drug designated for their respective group.

Individual comments in the focus group discussions indicate that the decision to take a drug designated as most effective for another race was based on (1) disbelief that drugs could be appropriately designated by race and (2) a strong suspicion of race-targeted medicine.

The lack of belief that medicine could be targeted by race was articulated in one group in this way: "You can't prescribe a drug for a group of people. You have to prescribe it for the individual. And that's what it sounds like it's doing, is prescribing for a group of people. You have to look at symptoms per person. .."(P\#8-004). Another group member agreed, "I went to this dermatologist about my skin and he said that this particular medicine works better on African American skin. I can understand that because my skin is darker than a White person's skin. But this about the heart.... I mean, I see a heart as a heart" (P\#8-016).

This widely held belief that drugs could not be successfully targeted to groups was due both to beliefs in the "melting pot" idea that individuals had ancestors whose previous continents of origin were multiple rather than singular and due to belief in within-group variation. As members of one group put it, "We have a little bit of everything mixed in. So how can you say, 'I guess you're mainly Black so I'll give you something... .” (P\#8100 ), and "Everybody in each racial group is not the same " (P\# 8-012). This disbelief is not irrational: it is grounded in the same insights that lead many scientists to question race-based medicine. It is also likely to be resistant to counter-persuasion because of the high levels of suspicion about the motives of race-based medicine.

Many participants articulated what they self-consciously called a "conspiracy" theory about the intent behind these messages. They believed that targeted medicine was a way to give African Americans an inferior product, or in the worst case scenario, even to produce genocide. The sentiment was expressed by one participant in this fashion:

"When he [another participant] mentioned the Tuskeegee experiment, I'm like, Oh, gad! This is... That's scary. I would have run the other way. I would. Simply for, I mean, our government's history in this country, I would seriously have to question, 'What are they trying to do to us now?' I really would. 'And what is the drug?' Is it going to kill more of us before we're 55? I mean, what's going on and historically" (P\#12-008).
As a result of these suspicions, many people were likely to feel unsafe taking a drug targeted for African Americans. Even among those who indicated that they would take the drug designated for their racialized group, the high levels of suspicion might have a substantial detrimental effect on patience compliance with prescribed medicines. Several participants suggested that they would "try out" the medicine, but discontinue it if they had side effects. For example, one African American female participant responded, "I would take it, but as soon as I had that first side effects, oh go back to the doctor Dalton, this happened, I would take it though, I'm open to any kind of medicine that is going to help me" (10-006).

Another example of someone who clearly indicated only conditional support for taking the drug designated for African Americans said, "For me, I would research it. I still do that anyway. When my doctor gives me a drug, I still go and find out.... I don't take it until I find out what it does, but not everyone does that" (12-008).

Although most participants would take the drug prescribed for their race initially, their levels of suspicion might lead to higher discontinuation rates. Disbelief in the underpinnings of race-based medicine combined with high levels of suspicion about motives thus suggests a serious barrier to patient uptake of race-based medicine.

\section{Attitude effects of discussing race-based medicine}

One of the major concerns about race-based medicine is that talking about race and genetics as though racial groups were correlated with discrete gene pools will reinforce a sense of difference between racial groups, essentializing race in ways that can encourage discrimination and social distance between groups. To assess the impact of the discussion on perceived genetic similarity, participants were asked two questions before and after the discussion. They were asked to rate the following statements on a 5 point scale from completely true (1) to completely false (5): "All Human Beings are $99.9 \%$ genetically the same" and "There is no biological basis for precise racial categorizations." During the discussion groups, an effort was made to present information in such a way as to counter perceptions of discrete genetic groups. For example, a chart presenting an example of group difference indicated that in Group A " $80 \%$ have version 1, $20 \%$ have version 2," while in Group B " $30 \%$ have version 1, 70\% have version 2." Moreover, the bulk of the comments made by participants expressed opposition to race-based medicine, and a common rationale given was that races were not discrete. In this context, the level of belief in genetic similarity among human beings (i.e., belief that the statement in question 1 is true) decreased from neutrality (2.61) in the prediscussion survey to mild disagreement (2.94) in the postdiscussion survey, and this difference was statistically significant at the 0.05 level (pre $S D=1.24$, post $S D$ $=1.35, t=-2.579, P=0.011)$. However, with regard to the more specifically race-focused statement, there was not a statistically significant change in mean attitudes, as the mean was roughly neutral before $(2.71, \mathrm{SD}=1.22)$ and after $(2.74, \mathrm{SD}=$ $1.18, t=-0.237, P=0.813)$ the discussion. 
The differential impact of the discussions-a change in the agreement about $99.9 \%$ similarity and no change with regard to race-appears to result from a strengthening of the familiarity with individual level differences in genetics and a resistance to racialized difference in genetics, especially among the African American groups. The emphasis on the individual level is used in many of the discussions as a means of resisting the treatment of race as based in fundamental and discrete differences ("essentialization"), as for example, by participant \#10010, who says "cause not every Black person has diabetes or high blood pressure or overweight, just like all White people don't have lupus, and the rest of the diseases." The same attitude is reflected in a relatively sophisticated exchange some participants used to "make sense" of the percentages the moderators had used to explain variation in genetics as a probabilistic relationship.

After one participant complained that it is just like assuming that you should serve a Black person chicken because of the stereotype that all Black people like chicken, another participant picked up the theme, and the group ran with it, saying "If there was a focus group that said, 'This group of people. . .70\% of them like chicken'.... They're saying, 'Well, we don't have time to figure out who likes what so we'll just make a menu of chicken because $70 \%$ of this group has shown we like chicken....When it comes to my medical care, I don't want to be $70 \%$ right" (P\#11-005).

These discussions of genetic disease and race thus appeared to have led to a highlighting of individual genetic differences, reflected in the change in score on the general variation question, but because these groups tended to have a high attentiveness to the variations within races, this did not translate into an increased perception of between-race difference. More research would be needed to explore that implication, its contextual boundaries, and generalizability.

\section{DISCUSSION}

The suitability of social race as a proxy for genetic variation in medical applications depends on a variety of factors. In part, it depends on the still disputed directness of the correlation between the two variables- genotype distributions and social labeling and grouping of "race." Although the scientific data describing the degree to which continental, clinal, and local variations are important in describing genetic variations remains incomplete, Table 2 indicates clearly that social characterizations of "race" are not fully captured by continental descriptors. Furthermore, the suitability of social race as a proxy for genetic variation depends on the specific features of the applications being made. Although the correlation between continental clusters and socially defined races may be sufficiently strong to serve the purposes of recruiting for inclusiveness in research protocols, the correlation may be insufficient for prescribing medicine or for diagnostic utility. ${ }^{14}$ In the case of prescription and diagnosis, one major factor will vary by particular condition, and that is the actual level of difference of frequency of appearance of relevant alleles in different popu- lations. Unless these differences are large, the utility of racebased prescription will not outweigh the impact of misassignment of individuals. For example, in research that reported on the effects of a drug treating heart failure, $14 \%$ of "Black" patients had health benefits and $49 \%$ of "White" patients received medical benefits from the drug. ${ }^{15,16}$ Characterizing this as though the drug "works" for one race and does not work for another is obviously an oversimplification that can have serious medical consequences. If almost $40 \%$ of the potential patients for the medication do not know the ancestry of all of their grandparents, the relative discrepancy of effectiveness from $14 \%$ to $49 \%$ may become moot.

Other major known genetic variations that affect drug uptake also display this kind of relatively low-level variation. For example, GP6D, which affects the response to a wide variety of drugs ranging from quinine to analgesics such as aspirin, to cardiovascular medications such as procainamide, varies in its frequency between $10 \%$ and $26 \%$ from those with ancestry exclusively in sub-Saharan Africa to $0.5 \%$ to $3.0 \%$ in Northern Europe, ${ }^{17}$ although the frequencies in Southern Europe can be higher. ${ }^{18}$ In Asia, the frequency varies from $0 \%$ to $10.8 \% .{ }^{19}$ These studies emphasize that the variation between populations of the same "race" is about as large as that between populations of different "races." In such cases, although the medical effect of having the allele is substantial, the relatively low frequency of the allele and its dispersed distribution make race unreliable as a marker for the allele and, therefore, for prescribing medicines.

The impact of the relatively low frequency of many of the medically significant alleles and of their mottled geographic dispersion is further exacerbated by the patient-side variables we have identified in this study. The ability to assign persons unambiguously to all of the racial groups that have significant input into their personal genetic configuration is a key requirement for the success of such prescription. The fact that a substantial minority of people most likely to be affected by issues of admixture do not know one or both of their biological parents $(8.9 \%)$ and that a surprisingly large group of people (39.6\% in this study) do not know all four of their grandparents, suggests a serious further limitation on the utility of racebased prescription. Although the over-representation of minority groups in our study means that these percentages are not likely to be representative of the general public, they may well be indicative of the order of magnitude of the problem for members of minority groups. This surprising finding also has implications for the limitation of family history in medical histories that deserves further investigation even if race-based pharmacogenomics becomes moot.

An additional difficulty lies in the serious suspicions that people have about drugs targeted to particular racial groups. Although the majority of people indicate that they would take the drug targeted for their group, there is a substantial minority for whom this is not the case. Moreover, our hypothetical offering of race-labeled drugs, although it might in fact mirror direct-to-consumer advertising, is unlikely to reflect real genetic inputs accurately for our Hispanic/Latino groups and self-designated multi-racial groups. This may be reflected by 
their higher preference for the "other" category. The disparity of responses in this issue between racial groups raises issues of justice. Race-based assignment of medicine would apparently allow European Americans to take drugs in which they have some confidence and which were more likely to be effective for them, whereas persons in other racialized groups would be forced to choose between drugs that were not as likely to be effective for them or in which they had no confidence. In contrast, direct genetic testing for the allele in question would deliver the benefits without the risks of race-based medicine.

Even for those who would accept the race-labeled drug consonant with their self-identified racialization, the high level of suspicion is likely to affect overall compliance and physicianpatient relations in negative ways. First, patients who are highly suspicious of a drug can be expected to be less likely to adhere to a drug over the long term, especially if that drug shows negative side effects that might confirm the lack of "safety" of a drug or if improvement in a condition is not immediate and obvious. Second, being told to take a medicine about which one is highly suspicious is not calculated to increase the trust between the medical profession and various racial groups, which has already been strained by a variety of historical and institutional factors. ${ }^{20}$

The problem of resistance to race-designated drugs might conceivably generate a recommendation that race-designation not be made a public matter. Whether or not advertisements and physicians could successfully be restrained from making such designations overt is one issue that would be raised in exploring such a recommendation. Another is the breach of trust that might be implied by such concealment, and the subsequent consequences of the disjunction between prescriptive professional literature and lay representations.

Finally, even if these barriers to delivery can be overcome, the impact of the discussions of race-based medicine might be so negative with regard to increasing the sense of racial differences that the disadvantages might outweigh the advantages on a social scale. This research does not provide a conclusive indication of the impact that talk about race-based medicine will have on attitudes about racial difference. Participants in this study were exposed to a consciously de-essentialized presentation of the material, and in that highly controlled condition, with a small sample, there was no increase in one measure of an attitude reflecting racial essentialization, although there was a significant decrease in perception of individual difference. In the broader society, the discourse will not be so tightly controlled. Moreover, the sample size in this study was too low to definitively rule out changes in racial attitudes, especially with regard to "White" participants, who are the group that may be the most prone to essentialization and most empowered to act on those essentializations in ways harmful to others. Additionally, a more sophisticated instrument for measuring genetic discrimination needs to be developed.

Taken together, these results suggest, at the least, that there will be substantial resistance to patient acceptance of racelabeled drugs and serious limitations on the ability to identify all of the ancestral lineages that might be relevant to a patient's genotype. These limitations and obstacles need to be weighed carefully given the availability of a good alternative-individual genotyping. Results from these focus groups also show ${ }^{21}$ that informed lay persons strongly prefer individual genetic testing and may be willing to shoulder substantial economic costs in preference to race-based prescription. Before a substantial commitment is made to race-based pharmacogenomics, additional attention to these patient-side issues is needed.

\section{Acknowledgments}

This research was supported by Grant No. 5 R01 HG02191-02 from the National Institutes of Health and by a University of Georgia Distinguished Research Professorship. The authors also wish to thank the Community Advisory Boards and the research participants for their thoughtful input into the research process.

\section{References}

1. Braun L. Race, ethnicity, and health: Can genetics explain disparities? Perspect Bio Med 2002;45:159-174.

2. Goodman AH. Why genes don't count (for racial differences in health). Am J Publ Health 2000;90:1699-1702.

3. Lee SS, Mountain J, Koenig BA. The meanings of "race" in the new genomics: implications for health disparities research. Yale J Health Policy Law Ethics 2001;1: 33-75.

4. Risch N, Burchard E, Ziv E, Tang H. Categorization of humans in biomedical research: genes, race and disease. Genome Bio 2002;3:2007.1-2007.12

5. Schwartz RS. Racial profiling in medical research. N Engl J Med 2001;344:1392-1393

6. Wilson JF, Weale ME, Smith AC, Gratrix F, Fletcher B, Thomas MG et al. Population genetic structure of variable drug response. Nat Genet 2001;29:265-269.

7. Wood AJJ. Racial differences in the response to drugs - pointers to genetic differences. N Engl J Med 2001;344:1393-1396.

8. Barbujani G, Magagni A, Minch E, Cavalli-Sforza L. An apportionment of human DNA diversity. PNAS USA 1996;94:4516-4519.

9. Halushka MK, Fan JB, Bentley K, Hsie L, Shen N, Weder A et al. Patterns of singlenucleotide polymorphisms in candidate genes for blood-pressure homeostasis. Nat Genet 1999;22:239-247.

10. Watkins WS, Ricker CE, Bamshad MJ, Carroll ML, Nguyen SV, Batzer MA et al. Patterns of ancestral human diversity: an analysis of alu-insertion and restrictionsite polymorphisms. Am J Hum Genet 2001;68:738-752.

11. Mountain J, Udina I, Gignoux C, Jobin M, Lin AA, Underhill PA et al. Ancien migrations indicated in global SNP/STR haplotype distributions. Am J Hum Gen 2002;71:178.

12. Marks J. Human biodiversity: Genes, race, and history. New York: Aldine de Gruyter, 1995.

13. Smedley BD, Stith AY, Nelson AR, editors. Unequal treatment: Confronting racial and ethnic disparities in health care. Washington, DC: National Academies Press, 2003.

14. Sankar P, Cho MK. Toward a new vocabulary of human genetic variation. Science 2002;298:1337-1338.

15. McLeod HL. Pharmacogenomics: More than skin deep. Nat Genet 2001;29:247-248

16. Exner DV, Dries DL, Domanski MJ, Cohn JN. Lesser response to angiotensin-converting-enzyme inhibitor therapy in black as compared with white patients with left ventricular dysfunction. N Engl J Med 2001;344:1351-1357.

17. Ethnasios RA. G6PD Deficiency and Favism Association Website. 2002. Available at: http://www.rialto.com/favism/index.htm. Accessed November 15, 2002.

18. Fiorelli G, Meloni T, Palomba V, Manoussakis C, Villa S, Cappellini MD. Gene frequency of glucose-6-phosophate dehydrogenase (G6PD) polymorphic variants in Sardinia. Gene Geog 1990;4:139-142.

19. Iwai K, Hirono A, Matsuoka H, Kawamoto F, Horie T, Lin K et al. Distribution of glucose-6-phosphate dehydrogenase mutations in Southeast Asia. Hum Genet 2001; 108:445-449.

20. Corbie-Smith G, Thomas SB, St George MM. Distrust, race, and research. Arch Intern Med 2002;162:2458-2463.

21. Bevan JL, Lynch JA, Dubriwny TN, Harris TM, Achter PJ, Reeder AL et al. Informed lay preferences for delivery of racially varied pharmacogenomics. Genet Med 2003; 5:393-399. 